University of Nebraska - Lincoln

DigitalCommons@University of Nebraska - Lincoln

\title{
The Extent of Online Platforms Utilization for Scholarly Research Work Dissemination: A Survey of Academic Staff in African Universities
}

\author{
Valentine Joseph Owan \\ University of Calabar, Nigeria, owanvalentine@gmail.com \\ Michael Ekpenyong Asuquo Ph.D \\ University of Calabar, Nigeria, mikeasuquo2015@gmail.com \\ Violet Makuku Ph.D. \\ vmakuku@gmail.com \\ Eno Etudor-Eyo Ph.D. \\ University of Uyo, Nigeria, enoetudor@gmail.com
}

Follow this and additional works at: https://digitalcommons.unl.edu/libphilprac

Part of the Educational Assessment, Evaluation, and Research Commons, Educational Technology Commons, and the Library and Information Science Commons

Owan, Valentine Joseph; Asuquo, Michael Ekpenyong Ph.D; Makuku, Violet Ph.D.; and Etudor-Eyo, Eno Ph.D., "The Extent of Online Platforms Utilization for Scholarly Research Work Dissemination: A Survey of Academic Staff in African Universities" (2021). Library Philosophy and Practice (e-journal). 5585.

https://digitalcommons.unl.edu/libphilprac/5585 


\title{
The Extent of Online Platforms Utilization for Scholarly Research Dissemination: A Survey of Academic Staff in African Universities
}

\author{
Valentine Joseph Owan $^{1}$, Michael Ekpenyong Asuquo ${ }^{1}$, Violet Makuku ${ }^{2}$, Eno Etudor-Eyo ${ }^{3}$ \\ owanvalentine@gmail.com; mikeasuquo2015@gmail.com; vmakuku@gmail.com; enoetudor@gmail.com \\ ${ }^{1}$ Department of Educational Management, University of Calabar, Calabar, Nigeria \\ ${ }^{2}$ Department of Research and Academic Planning, Association of African Universities, Ghana. \\ ${ }^{3}$ Department of Curriculum Studies, University of Uyo, Uyo, Nigeria
}

\begin{abstract}
An assessment of the extent of the use of electronic platforms by African academic staff in universities to disseminate research was done in this study. The study is informed by the growing importance of online repositories and preprint servers in the scientific communication of scholarly output, especially in an era where the use of metrics for research appraisals and funding decisions is commonly practised. The quantitative research method was adopted, based on the descriptive survey research design. The snowball sampling technique was used for data collection. Data were collected from 1,977 respondents, distributed across 24 African countries, through the use of an electronic survey. There was a high rate of willingness among universities' academic staff in Africa, to adopt various online platforms for research dissemination; ResearchGate is currently utilized the most for research dissemination, but Google Scholar is the platform respondents are more willing to adopt for research dissemination; the rate at which academic staff research output can be found online as a ratio of their total publication is $64.04 \%$ and in the ratio of 2.00:3.12; poor access to Internet facilities at home and workplaces are the major challenges academic staff face in the utilization of digital platforms for RD. It was recommended, amongst others that academic staff in universities should endeavour to explore and utilize at least ten of the online platforms mentioned in this study, to enable them disseminate their scholarly works to a wider audience and for increased visibility
\end{abstract}

Keywords: Academic staff, African Universities, online platforms, research dissemination, utilisation

\section{Declaration}

The authors declare that this is original research study carried out by the authors.

Funding: This study did not receive any external fund

Competing interests: The authors declare that they have no competing interest for this study.

Availability of data and material: The authors declare that the data of this study were obtained from primary sources through a survey (administration of questionnaires). The data used or analysed for this study are available from the corresponding author on reasonable request.

Authors' contributions: V. J. O. was instrumental in identifying the problem, building the background, design, data collection, instrument design and data collection and analysis, discussion of findings, editing and approving the manuscript. M.E.A. was responsible in drafting the manuscript, drafting the methodology, collection of data, editing and approving the manuscript. V. M participated in the data collection, data cleaning and curation, editing and approving the manuscript of the article. E. E-E participated in the design of the instrument, literature review, took part in data collection, revision and approval of the manuscript. 
Ethics Approval: Not applicable in this study.

Consent to participate: The consent to participate in this study was obtained from all participants and there was a clear agreement between the researchers and the participants that data obtained from them shall only be aggregated without the disclosure of personal identities. The analysis and presentation of results shall also be treated aggregately.

Consent for publication: All the participants agreed that the information provided can be published by the researchers so long as they are treated with confidentiality and at the aggregate level without the disclosure of their identities.

\section{Paper highlights}

1. There is a growing awareness of the usefulness of online platforms for RD.

2. University academic staff are willing to adopt these platforms for RD at varying degrees.

3. Many supported that digital platforms are more appropriate for RD than classical channels.

4. For every three works published by African universities' academic staff, two are on the internet.

5. No platform received zero utilisation, but the utilization rate varied across different platforms.

\section{Introduction}

Irrespective of the method(s) used, the process of conducting research include developing an idea for research and providing testable hypothesis, choosing research strategy, as well as data collection, analysis, interpretation of results and finally, communicating research results to other researchers and practitioners (Asim et al., 2017). The last step of the research process is in line with the popular adage in research that 'if it wasn't documented, it didn't happen...or did it?" (Ethicist, 2016, p.199). Similarly, it can be said that if research output is not communicated, then why was it conducted in the first place? This is because "the ability to supply research findings is the core business among knowledge producers such as universities and research centres (Naidoo, 211, pp. 47).” Publishing (communicating) research results is otherwise known as research dissemination (which is the central focus of the present study).

Research Dissemination (RD) is a coordinated phase that includes considering the intended groups and contexts in which research results are to be received and, where necessary, engaging and connecting with larger policy and service groups in ways that promote the uptake of data into decision-making processes and activities (Wilson et al., 2010). Innovative distribution of research means spreading more widely than conventional scholarly publications (e.g., universities, books, monographs) and meetings such as conferences and workshops (Ross-Hellauer, 2020). Contingent on the two definitions above, RD can be defined as a planned sequence of activities aimed at promoting the sharing of research results with the larger society using traditional and electronic means for increased visibility, usability, and application. The need to disseminate research findings cannot be over-emphasized (Herdon et al., 2011), since it is through this stage that research findings are publicized, implemented, problems addressed or key action decisions are taken.

Members of academic staff throughout the world, including those in African Universities, have at least three core functions of teaching, research and community service. Disseminating research findings, which appears as the final step in the research process, is a prevalent practice among scholars. It is a crucial aspect of the research process 
that scholars embark upon to ensure that knowledge is being transmitted to a wider community of intellectuals/researchers, policy-makers, government, private organizations, Non-Governmental organizations (NGOs), members of research institutions and ethical review communities, among others. Research work may not be considered as a complete and relevant project (that contributes to the bank of knowledge) until its findings or results are made available to the above-mentioned stakeholders. Disseminating educational research results does not only facilitate the visibility of the research results, but also the recognition and impact of the researchers. Results and recommendations arising from researches enhance end-users' innovative planning and decision-making, as well as assisting successive researchers to identify gap(s) that can motivate further researches for a sustained problem-solving framework (thereby making research a continuous process).

Traditionally, printed journals, magazines, conferences, books and other forms of academic materials in printed forms were the major outlets through which researches were disseminated. The classical approach is characterized only by physical attendance at conferences, seminars and workshops. Results of researches were only found in hard copies mostly in school, state and national libraries. In some cases, access to hard copies of research materials was only possible by order and postage (in cases where it was not possible to travel). Disseminating research results at one's comfort and travelling to gather research materials was a serious limitation in academia. It was a capital-intensive project which limited audience (academics, government and funding agencies, researchers, educational managers and planners, policy and decision-makers including practitioners) access to research results.

Technological advancement, has over the decades, ushered in a new paradigm in research communication/dissemination. The shift, in no small measure, has brought tremendous improvement to enhance the dissemination of research findings. Globalized access to scholarly literature, increased access to new knowledge, visibility of academics, plagiarism checks, speedy publication, as well as scholarly citation rate are now possible. Presently, blended RD (a combination of traditional and digital approaches) to communicate research results are being employed by researchers (Dahawy \& Kamel, 2017; Michel et al., 2013; Tveden-Nyborg, 2013). However, the conventional method in which scholars report their findings in academic papers (or monographs) focused on subscription still dominate, primarily due to the continued use of the publication venue's influence and reputation factor as a significant measurement indicator of academic efficiency and influence (Shearer, 2016).

The Internet and digitally networked technology have affected scientific RD in all aspects of life. The bulk of academic publications have migrated online in the last two decades, and academic books are steadily found on the web and in print (Ross-Hellauer, 2020). However, despite this transition, these common mechanisms of communication maintained relatively identical roles and formats. In a bid to disseminate research findings attractively and flexibly, individuals, groups of researchers, institutions and organizations make efforts to look for existing technologies (online platforms) that facilitate the dissemination of research results to take full advantage of them. Digital distribution could take place in several ways beyond the conventional formats, with more scholars using social networking (Bik \& Goldstein 2013; Jarreau, 2015; Yammine et al., 2017) and more than ten years of success of the use of blogs and Wiki as a specific method of "Open notebook science" (Bradley, 2007). Electronic databases, E-mail networks, Google Scholar and new web sites have been identified as ways of disseminating research results (Bougioukas et al., 2020; Duffy, 2000; Hibbert et al., 2020; Zientek et al., 2018). 
Communication tools (such as Blogging, Microblogging, Location, and Social Networking), collaboration tools (such as Conferencing, Wikis, Social Bookmarking, Social Bibliography, Social News, Social Documents, Project Management) and multimedia tools (such as Photographs, Video, Live streaming, Presentation Sharing and Virtual Worlds) can be used for online RD (Cann et al., cited in Cooper, 2014). To improve visibility of research findings, Tripathy et al (2017) identified Facebook, Linkedln, Blogs, Kudos, Google Scholar, ORCID, ResearchGate, Academia and Twitter as the necessary tools. Furthermore, blogs, websites and social media networks are interactive and cost-effective networking platforms which can be used to access scientists, professionals and the public beyond the conventional media (Gatewood et al., 2020).

Academic staff in recent years have indicated an interest in online platforms to evaluate their scholarly impact (Tripathy et al., 2017). The interest increases based on the fact that using online platforms for disseminating research results has the feature of global linkages (Duffy, 2000). The current trend, practices and criteria for promotion of academic staff in the university system, have in recent times, become one of the crucial factors that induce academic staff to adopt online tools as RD means, for the purpose of attracting citations and wider visibility. Besides, Odigwe et al. (2020) opined that the aim of retrieving and sharing research data is to solve problems, since available data at the disposal of other researchers can be used for further researches. Despite the numerous benefits brought about by innovations in $\mathrm{RD}$, many academics tend to have remained glued to traditional approaches and seem to have demonstrated unwillingness towards adopting new media in the dissemination of their research findings, despite the benefits associated with them. Notwithstanding the "so-many" disadvantages connected with traditional approaches to disseminating researches, many scholars are commonly observed using them.

The implication of this is that most often, the findings of their researches do not get to the target audience, resulting in poor visibility of their researches. Furthermore, many academics in developing countries, appear to have access to some of these electronic or digital resources, yet tend to be adamant and unskilled in utilizing, optimizing and maximizing their full benefits. This problem is not disconnected from the poor ICT skills and literacy rates of academics (Odigwe \& Owan, 2020). It was based on this problem that this study was conceived to assess quantitatively the rate at which academics are utilizing electronic channels for RD in African Universities.

Several empirical studies abound on the RD practices of academics and scholars the world over. A review identified Twitter, Facebook, LinkedIn, Snapchat, YouTube, Instagram and Periscope as modern ways in which pathologists use social media channels to strengthen scholarly work and promote the dissemination of information (Deeken et al., 2020). In North America, a study was conducted to survey academics' opinions on Wikipedia and open access publishing. It was found that academic staff inexperience was the reason for their negative opinions on open publishing through Wikipedia and open-access journals (Xiao \& Askin, 2014). However, sharing of research result among researchers has been made very easy through online platform (Sahin, et al., 2010; Tiemo et al., 2011). There was also a proposition that online platforms were used by academic staff in University to publish their instructional resources (Cheung \& Huang cited in Sahin et al., 2010).

Another study in Kenya indicated that the attitude of academic staff in respect of open access outlets in disseminating research results was on a negative direction because academic staff members thought that articles published in open access outlets were not given the necessary recognition in comparison to the ones published in 
conventional Journals (Mutwiri et al., 2017). Another research indicated that the extent of university academic staff utilization of internet facilities for teaching, research and record management was not high; their qualification, rank, gender as well as age influenced their utilization of internet facilities significantly (Odigwe \& Owan, 2020).

In a study, it was indicated among other findings, that academic staff used online tools mainly for their research (Bakare et al, 2015). It is well documented that the efficiency in the research process is facilitated by the utilization of online resources ( $\mathrm{Ng}$ et al. cited in Ani et al., 2015). Furthermore, online platform as part of technology increases access to information and its absence may slow down the rate of information dissemination (Shonhe \& Jain, 2017). Based on this, a study discovered in Tanzania that researchers in six public universities made more use of open access outlets to gain access to scholarly information than they utilize same in the dissemination of their scholarly outputs or the results of their research (Dulle \& Minishi-Majanja, 2009).

In a research, utilization of online resources was discovered to have had a substantial and positives consequence on the research productivity of academic staff in selected Nigerian Universities; substantial effect of utilization of online resources based on the area of specialization was not detected on the research productivity of academic staff; by gender, it was discovered that there was no substantial perceived effect of utilization of online resources on the academic staff research productivity (Ani et al., 2015). It was found by another study that data retrieval and sharing (dissemination) were significant in predicting the research effectiveness of academic staff about problem-solving, knowledge creation and the generation of testable data in higher education (Odigwe et al., 2020). In another study, it was discovered that ICT competence of academic staff was not encouraging thereby resulting in their low utilization of ICT tools for knowledge creation (Ekpoh \& Etor, 2012). Academic staff were found to have been utilizing e-mail services more in communicating their ideas as well as utilizing the internet for searching or data and publication (Uloaku, 2017).

A study also revealed academic staff awareness of online resources such as e-books, e-journals, and online databases was low; however, the study showed that academic staff were mostly aware of and utilized e-mail, online database and Internet services; a weak and negative correlation was also recorded between awareness and utilization of the online resources by the academic staff (Suleiman \& Joshua, 2019). The results of a study conducted in Brasil using a virtual snowball sampling technique and questionnaire indicated that Facebook ${ }^{\mathrm{TM}}$ is feasible to execute and analyze an experiment, easy to obtain low-cost responses, and promising for the collection and dissemination of information (Vieira et al., 2018).

To determine the efficacy of web-based platforms as powerful RD tools, a study was conducted with a focus on the Centre for Technology and Behavioural Health (CTBH) website. It was discovered that the website has given a list of 86 multimedia therapy programmes, including 447 empirical reports, and has been initiated by 70331 people, following the introduction of objective monitoring; the CTBH blog feed contains 1,160 postings, including 180 summaries of academic articles; 577 and 1,500 followers on the Twitter and Facebook accounts; the newsletter has entered a widespread subscriber network and strong transparency with business norms; the CTBH Online Presence acts as a blueprint for using open and quickly modified digital resources as channels of RD (Lord, et al., 2019). By implication, the digital delivery tools should improve conventional dissemination techniques to raise awareness about evidence-based digital therapy approaches to mental wellbeing and public health in general. 
A study used the dedication rate to measure the extent of public interest in dermatology on Facebook accounts. After a Facebook search that found many academic dermatology pages, the annual engagement was estimated for each page. Results showed that the consistent overall annual page interaction rate was 0.673 for scholarly publications, 0.313 for professional societies, and 1.563 for patient-centred entities, contributing to the finding that patient-centred groups interacted more successfully with their followers (Kim \& Vender, 2014). Another report indicated that 44 Research Brokering Organizations (RBOs) used additional internet techniques modestly; many of the techniques used are passive and do not facilitate two-way communication; thirty per cent of RBOs use social media; but this use is not widespread and there is little use of Twitter and Facebook networks (Cooper, 2014).

Another research used an online questionnaire to study researchers across three countries (Brazil, the United Kingdom, and the United States), with data combined to draw cross-country conclusions regarding the researchers' dissemination mechanism. The study observed, among other aspects, that traditional academic platforms were the primary dissemination methods; a number of variables were associated with self-assessed distribution efforts in the randomized sample, however these predictive factors (e.g. support and dissemination resources) were of low prevalence; less than one-third of participants graded their dissemination efforts as excellent; respondents acknowledged insufficient funding and tools to promote the dissemination of their results for researchers (Tabak et al., 2015). It was concluded that while intentions demonstrate the value of dissemination, researchers across countries lack support to improve distribution efforts; thus, increased resources and training Might help close the gap between research and practice in the design of dissemination along with strengthened partnerships.

Similarly, another research also used a digital poll to analyse the perception and motives of the public to engage in the distribution of sustainability information on LinkedIn and Twitter platforms. The LinkedIn and Twitter fact-based measures showing the reactions of the participants to the contents and formats were also analysed. Findings indicated that the highest participation and response rates were received in the infographic message format; participants used Twitter to develop broad awareness about sustainability when engaging in practical guidance on the development about group sustainability strategies on LinkedIn (Huang et al., 2019).

In a thorough review, Shearer (2016) classified web-based RD trends and innovations into various aspects of research such as Access \& Use (data mining, Interlinking and contextualization, content licensing, purchasing and payment modes), Publish (authoring and collaborative tools, journal selector and submission tools, peer review methods, publishing platforms), Share (data sharing, repository and journal aggregators, and researcher social networks), Evaluate (tracking research outputs, impact measures and journal quality assessment). Some of these innovations include OpenMinTeD and Digging into Data (data mining tools); Hypethes.is, Pubmed Commons (Interlinking, commenting and contextualization tools); Érudit Consortium and Canadian Research Knowledge Network, Association of Dutch Universities, SCOAP ${ }^{3}$, Max Planck Proposal (Innovations in content licensing); EDP Sciences, A study (Purchasing and payment modes); CoS Open Science Framework, F1000 workspace, Hivebench (Authoring and collaborative tools) (Shearer, 2016).

Furthermore, the listing was made including Edanz Editing, journal Author Name Estimator (Journal selector and submitter services); PubPeer, Episciences.org, Open Peer Review Module, The Winnower (Innovations in peer review); Frontiers, OpenScienceLink, PLOS ONE, Knowledge Unlatched, Open Library of Humanities (Publishing 
platforms); DataCITE, Gigajournal, Portage (Data sharing); OpenAIRE, LA Referencia, Érudit, Paperity, DeepDyve (Repository and journal aggregators); ResearchGate, Academia.edu, Mendeley (Researcher social networks); SHARE, OpenAIRE, CHORUS, Science 1 (Tracking research outputs); Impactstory, PlumX Metrics, A Times for Higher Education (Impact measures); Think, check, submit, Beall's list of journals that are predatory (Journal quality assessment) as innovative RD tools (Shearer, 2016).

The perceptions of the audience towards both online (two social networking sites: LinkedIn and Twitter) and offline contact networks (conferences) were first analyzed in a research. Then, in pairs, the efficacy of each channel was compared. Findings showed that, overall, respondents to the survey displayed favourable attitudes toward all three systems, but have more favorable outlook towards conferences than two social networking platforms (Twitter and LinkedIn); conferences has undeniable benefits over LinkedIn and Twitter in terms of higher service efficiency, wordof-mouth, user participation, and message persuasiveness; the responses of the survey participants to these two social networking platforms, LinkedIn and Twitter, were found to be very similar; meanwhile, Twitter performed marginally better overall than LinkedIn in terms of disseminating the same data on the adoption of sustainable city plans (Tian, 2015).

Another analysis has shown that the use of social media was positively affected by the engagement of participants in joint research activities; researchers who collaborated with colleagues in various organizations were more frequent users of social media (73 per cent), accompanied by researchers working as part of a joint team (68 per cent frequent users); researchers who engaged in larger, discipline-based research networks have used social media platforms more frequently (57 per cent frequent users) as well as researchers who used participated in the informal urban research network (55\% regular users); researchers who have not been involved in collective studies are much less likely ( 9 per cent regular users) to use social media platforms regularly (Proctor et al., 2010).

The research by De Queiroz et al. (2016) analyzed the methods used to incorporate science dissemination in their contact practices by the top 50 Brazilian universities. To do this, the website of each university was reviewed to gather a wide sample of institutions that organise and prioritize the dissemination of research in education and science and to make their studies and programs accessible to the public. Only 15 universities were found to emphasize the dissemination of research; 11 of those universities are among the top 25 in the country; it was noted that there is a clear correlation between academic quality and the dissemination of research.

\section{The present study}

The present study is informed by the need to investigate the extent to which electronic/online tools are being utilized by African scholars for the dissemination of research output in higher education. The review of the literature suggests that the topic of RD has attracted a lot of attention globally. A growing body of researches tend to be focused on explaining the importance of RD (Bik \& Goldstein 2013; Boyd \& Ellison, 2007; Cabrera et al., 2017; Deeken et al., 2020; Duffy, 2000; Jarreau, 2015; Yammine et al., 2017). Other studies have also focused on explaining several social media platforms as channels of RD (De Queiroz \& Becker, 2016; Dong et al., 2020; Huang et al., 2019; Proctor et al., 2010). Having explored the various findings and positions held by past studies, it was discovered that little or nothing 
seems to have been documented about the extent to which African academic staff in institutions of higher learning utilize electronic/digital tools for the dissemination of researches.

This research is an attempt to fill this void, among other areas where there appears to be a paucity of research literature. Within the context of Africa specifically, this study also seems to be first or among the very few to assess the utilization of online tools for RD. Consequently, this study has been designed with the following specific research objectives such as to assess the extent academic staff are willing to adopt online platforms for RD; determine the proportion of academic staff that still find classical platforms as appropriate channels for RD; discover the online tools that academic staff are utilizing for RD as well as the extent of utilization; compute the rate at which academic staff research output as a ratio of their total publication can be found online; identify the challenges faced by academic staff in the utilization of online platform for RD.

Based on these objectives, the present study was designed to answer the following research questions:

1. to what extent are members of academic staff willing to adopt online platforms for RD?

2. what proportion of academic staff still finds classical platforms as more appropriate for RD?

3. what online tools are members of academic staff utilizing for RD and to what extent?

4. What is the rate at which academic staff research output can be found online as a ratio of their total publication?

5. What are the challenges faced by academic staff in the utilization of online platforms for RD?

\section{Methods}

This is a quantitative study that was designed based on the descriptive survey research architecture. The population of this study comprised all the Universities' Academic Staff in the 54 African countries. The virtual snowball sampling technique was used to target a few scholars in universities located at different African regions - East, West, North and South. Thereafter, the scholars were expected to share the survey to other colleagues within and outside their universities. The non-probability sampling technique (virtual snowball or chain referral) was chosen because the researchers could not make physical contact with all the academic staff in universities. It was also not possible for the researchers to create a sample frame based on the geographical dispersion of targeted respondents as well as the means of data collection. According to some scholars, "Snowball sampling is often employed when no sampling frame can be constructed" (Kirchherr \& Charles, 2018, p. 2).

The use of snowballing technique has been documented as having the possibility of increasing the representativeness of results (Baltar \& Brunet, 2012) and the snowball approach is inevitable in studies based on social networks (Atkinson \& Flint, 2004). Furthermore, the researchers were interested in only making generalisations to the participants (sample) of the study and not the population, justifying the use of the sampling technique. Scholars who are grounded in quantitative thinking, tend to interpret the drawing of a random sample as the data collection gold standard in quantitative studies (Lijphart, 1971; King et al. 1994). However, even these scientists may also consider methods of non-probability sampling, such as snowball sampling, a 'necessary and irreplaceable sampling method' (Waters 2015, p. 367), when faced with populations that are difficult to access, especially if the rejection of snowball sampling would indicate that no study could be carried out at all (Kirchherr \& Charles, 2018). 
An electronics survey - "Utilisation of Online Platforms for Research Dissemination Questionnaire (UOPRDQ)", with three major sections, was used for data collection. Section one contained a detailed cover letter explaining the purpose of the research, its scope, the expected completion time, the quality of response/data required and an ethical statement indicating how the data shall be treated to ensure anonymity and confidentiality. Section two was designed to collect respondents' demographic data such as gender, age, educational qualification, rank, years of work experience, research areas and country of residence. Section three was divided into six sub-sections. The first sub-section is a five-point rating scale, with a list of 20 online platforms that participants were expected to indicate the extent to which they were willing to adopt them for RD. The second sub-section was a closed-ended question devoted to understanding staff perception of using traditional versus modern approaches to RD. The third sub-unit was a checklist containing 20 online platforms for respondents to tick the ones they currently utilize for RD.

The fourth sub-section was designed to find out respondents' total number of academic publications (including journal articles, Theses/Dissertation, Conference papers, chapters in books and books). The fifth sub-unit was dedicated to finding out the total number of respondents' scholarly works that are currently visible on the internet (including those on publishers' websites and those they uploaded by themselves to online platforms). The sixth subunit of section three was designed to allow respondents express their opinions on the challenges they encounter trying to utilize online platforms for research dissemination. The instrument was vetted by three experts of educational technology and two psychometrists in the Faculty of Education, University of Calabar, Nigeria for face and content validity.

The e-survey was posted on the Association of African Universities' Telegram group, with currently 1,622 members from different African countries and regions. Members, who were universities' academic staff in the group, were asked to take the survey and share the same on their institutions' internet-based forums. Data were collected from July 2020 to January 2021 when the survey was closed, indicating a seven months data collection duration. After closing the survey, the associated data was downloaded, converted to an Excel document (.xlsx), assessed, cleaned and re-coded (where necessary). A total of 1,977 academic staff in African universities responded to the survey (their demographic information is presented the results section). Descriptive statistics such as frequency counts, simple percentage, mean, and standard deviation were used in the analysis of data; while pie charts and bar charts were used for illustrative purposes, especially to non-statisticians.

\section{Results}

\section{Respondents' demographics}

The demographic analysis of respondents indicated that 1347 (68.13\%) of the respondents were males while 630 (31.87\%) were females (See Fig. 1). A total of $180(9.10 \%)$ of the respondents were in the 20 to 29 years age category; $450(22.76 \%)$ were between 30 and 39 years; 627 (31.71\%) were between 40 and 49 years; 360 (18.21\%) were between 50 to 59 years; while $360(18.21 \%$ ) were 60 years or above (See Fig. 2). In terms of educational qualification, 90 $(4.55 \%)$ of the respondents were first degree holders; 630 (31.87\%) were master's degree holders; while 1,257 $(63.58 \%)$ were doctorate holders (See Fig. 3). For rank, results indicated that 180 (9.10\%) of the respondents were graduate assistants, $270(13.66 \%)$ were assistant lecturers; 450 (22.76\%) were grade II lecturers; 180 (9.10\%) were 
lecturers in grade I; 360 (18.21\%) were senior lecturers; 357 (18.06\%) were associate professors/readers; while 180 $(9.10 \%)$ were full professors.

In terms of the years of work experience (see Fig. 5), 180 respondents (representing $9.10 \%$ of the respondents) indicated that they have less than three years of work experience. Those with three to six years of work experience were $630(31.87 \%)$. Also, another 180 respondents $(9.10 \%)$ indicated that they have between seven and ten years of work experience. However, majority of the respondents (987 representing 49.92\%) expressed that their years of work experience is 11 years or above (See Fig. 5). In terms of the research areas of respondents, $360(18.21 \%)$ were in the arts and humanities category; 177 (8.95\%) were in the general education category; 90 (4.55\%) were specifically in the educational administration and planning, as well as the educational technology categories respectively; 180 (9.10\%) were in management and medical sciences categories respectively; $360(18.21 \%)$ were in the pure/applied sciences research area category; while $540(27.31 \%)$ were in the social sciences research area category (See Fig. 6).

In terms of respondents' country of residence, results disclosed that six respondents $(0.30 \%)$ were residents of Algeria; 17 respondents $(0.86 \%)$ were residents of Benin Republic; 15 participants representing 0.76\% were residents of Botswana; while 24, 9, 14, 54, 58, 11 and 18 respondents representing $1.21 \%, 0.46 \%, 0.71 \%, 2.73 \%$, $2.93 \%, 0.56 \%$ and $0.91 \%$ were residents of Cameroon, Egypt, the Gambia, Ghana, Kenya, Lesotho, and Liberia respectively (See Fig. 7). Furthermore, it was revealed that 14 respondents $(0.71 \%)$ were residents of Mauritius; 15 respondents $(0.76 \%)$ were residents of Namibia; while $32,16,8,17,9$, and 28 respondents representing $1.62 \%, 0.81 \%$, $0.40 \%, 0.86 \%, 0.46 \%$ and $1.42 \%$ were residents of Niger Republic, Rwanda, Senegal, Seychelles, Sierra Leone, and South Africa respectively (See Fig. 7). The country analysis further showed that Sudan, Tanzania, Uganda, Zambia, and Zimbabwe were represented by in the study by $14(0.71 \%), 13(0.71 \%), 18(0.91 \%), 22(1.11 \%)$, and $84(4.25 \%)$ respondents accordingly (See Fig 7). Nigeria had the highest of representation, with a total number of 1461 respondents, representing $73.90 \%$ of the total participants.

\section{Research question 1}

To what extent are members of academic staff willing to adopt online platforms for RD? Generally, the results in Table 1 indicated that there is a high extent of willingness among the respondents to adopt online platforms for research dissemination $\left(\sum=5839, \bar{X}=3.03, \mathrm{SD}=1.69\right)$. More specifically, academic staff of universities in Africa also indicated a high degree of willingness to adopt ResearchGate $\left(\sum=8814, \bar{X}=4.46, \mathrm{SD}=0.89\right)$, Google Scholar $\left(\sum=\right.$ 8901, $\bar{X}=4.50, \mathrm{SD}=0.78)$, ORCID $\left(\sum=6027, \bar{X}=3.05, \mathrm{SD}=2.01\right)$, Mendeley $\left(\sum=6570, \bar{X}=3.32, \mathrm{SD}=1.91\right)$, Academia.edu $\left(\sum=7290, \bar{X}=3.69, \mathrm{SD}=1.54\right)$, Facebook $\left(\sum=5670, \bar{X}=2.87, \mathrm{SD}=1.98\right)$, LinkedIn $\left(\sum=5670, \bar{X}=\right.$ 2.87, $\mathrm{SD}=1.79)$, Telegram $\left(\sum=5940, \bar{X}=3.00, \mathrm{SD}=1.53\right)$, Blogs $\left(\sum=5220, \bar{X}=2.64, \mathrm{SD}=1.82\right)$, YouTube videos $\left(\sum=5940, \bar{X}=3.00, \mathrm{SD}=1.88\right)$, Electronic mail $\left(\sum=8091, \bar{X}=4.09, \mathrm{SD}=1.16\right)$, Institutional repositories $\left(\sum=\right.$ $6840, \bar{X}=3.46, \mathrm{SD}=1.72)$, ZOOM Videoconferencing $\left(\sum=7020, \bar{X}=3.55, \mathrm{SD}=1.90\right)$, and Pre-print servers such as BioRxiv, arXiv, Chemrxiv, the winnower, PsyArXiv, PrePubMed $\left(\sum=5580, \bar{X}=2.82, \mathrm{SD}=1.97\right)$ for research dissemination in African Universities (See Table 1). However, academic staff of universities in Africa indicated a low extent of willingness (in Table 1) in adopting the following online platforms for research dissemination in African 
Universities: Publons $\left(\sum=4860, \bar{X}=2.46, \mathrm{SD}=1.97\right), \mathrm{SSRN}\left(\sum=4680, \bar{X}=2.37, \mathrm{SD}=2.01\right)$, Calameo $\left(\sum=3870\right.$, $\bar{X}=1.72, \mathrm{SD}=2.95)$, BePress $\left(\sum=3960, \bar{X}=2.00, \mathrm{SD}=1.76\right)$, Twitter $\left(\sum=4860, \bar{X}=2.46, \mathrm{SD}=1.75\right)$ and PhilPapers $\left(\sum=3960, \bar{X}=2.00, \mathrm{SD}=1.73\right)$. The results further indicated that the online platform that academic staff are most interested and willing to adopt is the Google Scholar platform while the least is Calameo.

\section{Research question 2}

What proportion of academic staff still finds classical platforms as more appropriate for RD? In this research question, respondents were asked if they think that the use of classical approaches/platforms such as traditional printing of books, journals, physical travels to conferences, indexing of scholarly works in traditional institutional libraries and so on, are more appropriate for research dissemination than the use of modern electronic/online platforms. The result in Fig. 8 revealed that 720 academic staff, representing $36.42 \%$ of the total distribution, still considered classical platforms as more appropriate for research dissemination than modern approaches. On the contrary, the result indicates that 1,167 academic staff in African universities, representing 59.03\% of the total distribution, do not find classical platforms as being more appropriate for dissemination than modern platforms. However, a total of 90 academic staff in universities representing $4.55 \%$ of the respondents were fence-sitters, as they neither agreed nor disagreed that classical platforms are more appropriate for research dissemination.

\section{Research question 3}

What online tools are members of academic staff utilizing for RD and to what extent? The results of the analysis indicate that respondents adopted ResearchGate, Google Scholar, Academia.edu, ZOOM videoconferencing, Telegram, ORCID, Facebook, LinkedIn, Mendeley, E-mail, YouTube videos, Institutional repositories, BePress, Twitter, Publons, SSRN, pre-print servers, Blogs, Calameo and PhilPapers to an extent of $81.34 \%, 72.89 \%, 45.52 \%$, $33.38 \%, 27.31 \%, 23.67 \%, 22.76 \%, 21.40 \%, 20.59 \%, 20.38 \%, 14.82 \%, 13.86 \%, 13.66 \%, 13.66 \%, 11.08 \%, 6.88 \%$, $6.32 \%, 3.89 \%, 3.03 \%$ and $0.71 \%$ respectively (in descending order of utilization; see Fig. 9 and Table 2). If the average mark is set at $50 \%$, the results imply that only the extent to which respondents utilized ResearchGate and Google Scholar would be considered as high, while the rest of the platforms were utilized to a low extent.

\section{Research question 4}

What is the rate at which academic staff research output can be found online as a ratio of their total publication? In an attempt to answer this research question, the researchers took stock of the total number of scholarly work (including Journal Articles, Theses/Dissertation, Conference Papers, Chapters in Books and Books Published) that respondents have published, as well as the total number that are currently on the internet (including those on publishers' websites and through personal upload to different repositories or databases). At the aggregate level, the result showed that the 1,977 respondents who participated in this study have published a total of 67,179 scholarly works. Out of these, 43,019 are currently on the internet. This implies that $64.04 \%$ of the published works by the respondents can be found currently on the internet. We can mathematically express this in ratio form as 43019:67179 or 43,019/67,179. 
Dividing both the numerator and denominator by an HCF of 21,509 reduces the fraction to a ratio of 2.00:3.12 or $2.00 / 3.12$.

\section{Research question 5}

What are the challenges faced by academic staff in the utilization of online platforms for RD? The result of the analysis (presented in Fig. 10 and Table 3) indicated that the challenges faced by universities' academic staff in the utilization of online platforms for research dissemination include inconsistent electricity supply (36.42\%), no/poor access to internet facilities at home (49.92\%), unstable connection by internet service providers (40.82\%), insufficient ICT knowledge or internet operational skills $(31.71 \%)$, poor awareness of online platforms for research dissemination (31.71\%), poor job motivation (27.31\%), inadequate supply of internet at the workplace (49.92\%), tight schedules of duties and operations $(27.16 \%)$, poor conviction on the benefits of electronic platforms (13.66\%) and perception and resistance (e.g., believe that the internet is meant for younger generations, 8.95\%). Furthermore, some respondents identified other challenges to include high cost of internet bundle and subscription rates (44.31\%), excessive data consumption by internet service providers $(32.73 \%)$, and poor income level which hinders the procurement of cuttingedge devices and gadgets to facilitate online presence $(4.55 \%)$.

\section{Discussion and conclusion}

This research discovered that the academic staff of universities in Africa indicated a high degree of willingness to adopt internet platforms for research dissemination. Specifically, staff are highly interested in adopting electronic platforms such as Google Scholar, ResearchGate, Email, Academia.edu, Zoom videoconferencing, Institutional repositories, Mendeley, ORCID, Telegram, YouTube videos, Facebook, LinkedIn, Pre-print servers, Blogs, Publons Twitter, SSRN, Bepress, PhilPapers and Calameo (in descending order of interest) for RD in African Universities. This finding may be attributed to the growing awareness among scholars of the usefulness of ICT generally, and the internet specifically in promoting academic activities. This aligns with the position of a study which indicated that there is a gradual increase regarding how ICTs are used in Nigeria and many other African countries (Odigwe \& Owan, 2020). The finding also validates the results of a recent study which revealed that academic staff in recent years have indicated an interest in online platforms to evaluate their scholarly impact (Tripathy et al., 2017).

In agreement with the results of Odigwe and Owan (2020), the present study indicated that there is a high level of awareness among staff of universities in Africa on the benefits of utilizing online platforms for RD. This is reflected in their high preference for modern rather than classical approaches/platforms for research dissemination. The high level of awareness uncovered in this study may be attributed to the extensive body of literature explaining the importance of ICT in education in Africa and beyond (see for example Basri, et al., 2018; John, 2015; Jumbo, 2019; Maisamari, et al., 2018; Owulu, et al., 2016). Interestingly, the high rate of awareness could also be the reason why none of the enlisted online platforms received a zero utilisation rate. Although ResearchGate was found in this study as the most currently utilized electronic platform for RD among universities' academic staff in Africa, most respondents are more prepared in the future to embrace Google Scholar. This implies that in the future, we may see a rise in the rate of Google Scholar utilization among other online platforms. 
From our analysis, we determined that the rate at which academic staff research output can be found online as a ratio of their total publication is 2.00:3.12. Implying that out of every 3.12 published works by academic staff of universities in Africa, 2.00 are online. However, it makes no sense to say there can be 3.12 published works since it is impractical for a person to disseminate a fractional number of scholarly works. Therefore, attempting to round-off the values to the nearest whole number, could leave you with a ratio of 2:3 (which makes more sense to say for every three published works by scholars, two are online). Even at this point, care must be taken because ratio deals with equality, therefore, rounding off fractional components that are not of equal magnitude is misleading (e.g., $.00 \neq .12$ to round off under ratio rules). Thus, sticking with the factional ratios gives a mental picture of the distribution. Based on this, we concluded that out of approximately every three published scholarly works by academic staff of universities in Africa, approximately two are online.

This study faces the limitation of inadequate methodological robustness, as the study's design did not allow the researchers to elicit from the respondents, reasons for their high level of willingness as well as preference in the utilization of some online platforms over others. Secondly, the study adopted a non-probability sampling approach indicating that there was no fairness in the selection of participants, however, considering that the sample is relatively large and cuts across 24 African countries, there is a likelihood of sample representativeness. This is not a major weakness since the researchers did not generalize the results obtain to the larger population, rather analysis and generalizations were based on the study's respondents. Based on these limitations, it is recommended that prospective researchers should adopt the mixed methods design and the proportionate stratified sampling technique for more insights and effective population representation.

\section{Conclusion}

It was concluded that there is a currently a high rate of academic staff utilization of online platforms for research dissemination in African universities. Despite the high rate of utilization, many members of staff are yet willing to adopt these platforms for research dissemination. This has future implications on the utilization rates of online platforms for RD, which is likely to increase yet further. No/poor access to internet facilities at home and inadequate supply of internet at workplaces are the major challenges academic staff face in the utilization of digital platforms for research dissemination. The following recommendations are hereby proposed, based on the conclusion of this study:

1. Academic staff in universities should endeavour to explore and utilize at least ten of the online platforms mentioned in this study, to enable them to disseminate their scholarly works to a wider audience and for increased visibility.

2. Members of academic staff who do not own electronic infrastructure necessary to enable them to disseminate their scholarly works on the internet, should try as much as possible to save a portion of their income for the acquisition of relevant gadgets for RD purposes;

3. Members of academic staff should develop the habit of making sure that 100 per cent of their published works (including pre-prints) are always uploaded across multiple platforms so long as they have the copyright to do so. Doing this will increase the utilization rate of internet platforms, readership and increased chances of citations; 
4. African university managers and supporting agencies should ensure that internet facilities and services are provided to universities for optimal utilization by academics for RD and other purposes.

5. There should be consistent electricity supply in all African universities to eliminate the problem of unstable electricity.

6. Staff with little or no knowledge of the use of present-day ICT devices should take themselves forward by enrolling in computer training programmes to acquire these important skills; while those with the perception that "ICT devices are meant for the younger generations" should discard such perception and embrace it fully, especially for research communication.

\section{References}

Ani, O. E., Ngulube, P., \& Onyancha, B. (2015). Perceived effect of accessibility and utilization of electronic resources on the productivity of academic staff in selected Nigerian Universities. SAGE Open, 2015, 1-7. https://doi.org/10.1177/2158244015607582

Asim, A. E., Idaka, I. E., \& Eni, E. I. (2017). Research in education: Concept and techniques. University of Calabar Press.

Atkinson, R., \& Flint, J. (2004). Encyclopedia of social science research methods (pp. 1044-1045). SAGE Publications, Inc.

Bakare, O. D., Chiemenem, C. M., Bamigboye, O. B., \& Okonedo, S. (2015). Social media tools as a medium for knowledge sharing among students and academic staff of Nigerian Universities: Case Study of Students' and Academic Staff of the Federal University of Agriculture, Abeokuta, Ogun State, Nigeria. New Media and Mass Communication, 35, 35-46. https://bit.ly/3kNyvHy

Baltar, F., \& Brunet, I. (2012). Social research 2.0: Virtual snowball sampling method using Facebook". Internet Research, 22(1), 55-74. https://doi.org/10.1108/10662241211199960

Basri, W. S., Alandejani, J. A., \& Almadani, F. M. (2018). ICT adoption impact on students' academic performance: Evidence from Saudi universities. Education Research International, 9(2), 1-10. https://doi.org/10.1155/2018/1240197

Bik, H. M., \& Goldstein, M. C. (2013). An introduction to social media for scientists. PLoS Biology, 11(4), e1001535. https://doi.org/10.1371/journal.pbio.1001535

Bougioukas, K. I., Bouras, E. C., Avgerinos, K. I., Dardavessis, T., \& Haidich, A. B. (2020). How to keep up to date with medical information using web-based resources: A systematised review and narrative synthesis. Health Information \& Libraries Journal, 37(4), 254-292. https://doi.org/10.1111/hir.12318

Boyd, D. M., \& Ellison, N. B. (2007). Social network sites: Definition, history, and scholarship. J Comput Mediat Commun., 13(1), 210-230. https://doi.org/10.1111/j.1083-6101.2007.00393.x

Bradley, J. (2007). Open notebook science using blogs and wikis. Nature Precedings, 2007, 39. https://doi.org/10.1038/npre.2007.39.1

Cabrera, D., Vartabedian, B. S., Spinner, R. J., Jordan, B. L., Aase, L. A., \& Timimi, F. K. (2017). More than likes and tweets: Creating social media portfolios for academic promotion and tenure. Journal of Graduate Medical Education, 9(4), 421-425. https://doi.org/10.4300/JGME-D-17-00171.1

Cooper, A. (2014). The use of online strategies and social media for research dissemination in education. Education Policy Analysis Archives, 22(88). https://doi.org/10.14507/epaa.v22n88.2014

Dahawy, K., \& Kamel, S. (2017). Using blended techniques in knowledge dissemination: Lessons learnt from the case of the American University in Cairo. The Electronic Journal of Information Systems in Developing Countries (EJISDC), 37(1), 1-12. https://doi.org/10.1002/j.1681-4835.2009.tb00259.x 
De Queiroz, G. B. R., \& Becker, V. (2016). The dissemination of science and science journalism in Brazilian universities: Analysing strategies that facilitate access to Science \& Technology. Brazilian Journalism Research, 12(3), 170-189. https://doi.org/10.25200/BJR.v12n3.2016.888

Deeken, A. H., Mukhopadhyay, S., \& Jiang, X. S. (2020). Social media in academics and research: 21st-century tools to turbocharge education, collaboration, and dissemination of research findings. Histopathology, 77, 688- 699. https://doi.org/10.1111/his.14196

Dong, J. K., Saunders, C., Wachira, B. W., Thoma, B., \& Chan, T. M. (2020). Social media and the modern scientist: a research primer on social media-based research, dissemination, and sharing. African Journal of Emergency Medicine, In Press. https://doi.org/10.1016/j.afjem.2020.04.005

Duffy, M. (2000). The internet as a research and dissemination resource. Health Promotion International, 15(4), 349353. https://doi.org/10.1093/heapro/15.4.349

Dulle, F., \& Minishi-Majanja, M. (2009). Researchers' perspectives on open access to scholarly communication in Tanzanian public universities. SA Journal of Information Management, 11(4), a413. https://doi.org/10.4102/sajim.v11i4.413

Ekpoh, U. I., \& Etor, C. R. (2012). Academic staff utilization of information and communication technology and knowledge creation in Cross River State Universities. African Higher Education Review (AHER), 6, 38-45. https://bit.ly/32RIF3K

Ethicist, P. (2016). If it wasn't documented, it didn't happen . . . or did it? Journal of Empirical Research on Human Research Ethics, 11(2),199-200. https://doi.org/10.1177/1556264616654055

Gatewood, J., Monks, S. L., Singletary, C. R., Vidrascu, E., \& Moore, J. B. (2020). Social media in public health: strategies to distil, package, and disseminate public health research. Journal of Public Health Management and Practice, 26(5), 489-492. https://doi.org/10.1097/PHH.0000000000001096

Hibbert, P., Saeed, F., Taylor, N., Clay-Williams, R., Winata, T., Clay, C., Hussein, W., Braithwaite, J. (2020). Can benchmarking Australian hospitals for quality identify and improve high and low performers? Disseminating research findings for hospitals. International Journal for Quality in Health Care, 32(1), 84-88. https://doi.org/10.1093/intqhc/mzz109

Huang, L., Clarke, A., Heldsinger, N., \& Tian, W. (2019). The communication role of social media in social marketing: A study of the community sustainability knowledge dissemination on LinkedIn and Twitter. Journal of Marketing Analytics, 7, 64-75. https://doi.org/10.1057/s41270-019-00053-8

Jarreau, P. (2015). All the science that is fit to blog: An analysis of science blogging practices. LSU Doctoral Dissertations. https://bit.ly/32XseTw

John, S. P. (2015). The integration of information technology in higher education: A study of faculty's attitude towards IT adoption in the teaching process. Contaduría y Administración, 60(1), 230-252. https://doi.org/10.1016/j.cya.2015.08.004

Jumbo, M. E. (2019). Lecturers' characteristics on the Utilization of ICTs Services in College of Health Technology, Calabar, Cross River State, Nigeria. International Journal of Innovative Research \& Development, 8(8), 7281. https://doi.org/10.24940/ijird/2019/v8/i8/AUG19039

Kim, W., \& Vender, R. (2014). Use of Facebook as a tool for knowledge dissemination in dermatology. Journal of Cutaneous Medicine and Surgery, 18(5), 341-344. https://doi.org/10.2310/7750.2014.14022

King, G., Keohane, R. O., \& Verba, S. (1994). Designing social inquiry: Scientific inference in qualitative research. Princeton University Press. https://doi.org/10.1515/9781400821211

Kirchherr, J., \& Charles, K. (2018). Enhancing the sample diversity of snowball samples: Recommendations from a research project on anti-dam movements in Southeast Asia. PloS One, 13(8), e0201710. https://doi.org/10.1371/journal.pone.0201710

Lijphart, A. (1971). Comparative politics and comparative method. Am Polit Sci Rev., 65, 682-693. https://doi.org/10.2307/1955513 
Lord, S. E., Seavey, K. M., Oren, S. D., Budney, A. J., \& Marsch, L. A. (2019). Digital presence of a research centre as a research dissemination platform: Reach and resources. JMIR Ment Health, 6(4), e11686. https://doi.org/10.2196/11686

Maisamari, A. M., Adikwu, V. O., Ogwuche, C. O., \& Ikwoche, F. (2018). Assessment of secondary school teachers' use of Information and Communication Technology (ICT) in Anyingba Metropolis, Kogi State, Nigeria. Journal of Education and Entrepreneurship, 5(1), 32-47. https://doi.org/10.26762/jee.2018.40000010

Michel, M. E., Pintello, D. A., \& Subramaniam, G. (2013). Blending research and practice: an evolving dissemination strategy in substance abuse. Social work in public health, 28(3-4), 302-312. https://doi.org/10.1080/19371918.2013.774660

Morgan, G. A., Gliner, J A., \& Harmon, R. J. (1999). Definition, purposes, and dimensions of research. Journal of the American Academy of Child \& Adolescent Psychiatry, 38(2), 217219. https://doi.org/10.1097/00004583$\underline{199902000-00023}$

Mutwiri, C., Karia, M., \& Muriungi, C. (2017). Academic staff attitude towards open access outlets in disseminating research findings in selected Universities in Kenya. International Research, 6(2), 56-64. https://bit.ly/3fbFI2Y

Naidoo, N. (2011). What is research? A conceptual understanding. African Journal of Emergency Medicine, 1, 47-48. https://doi.org/10.1016/j.afjem.2011.05.011

Odigwe, F. N., \& Owan, V. J. (2019). Data management practices and educational research effectiveness of university lecturers in South-South Nigeria. In C. A. Shoniregun (Ed.), London International Conference on Education (LICE-2019) (pp. 86-94). Infonomics Society. https://doi.org/10.2053/LICE.2019.0021

Odigwe, F. N., \& Owan, V. J. (2020). Academic staff personal variables and utilization of ICT resources for research, teaching and records management in higher education. Proceedings of the 8th Annual European Conference on Education (ECE, 2020), 107-123. https://bit.ly/2GG36II

Owulu, E. E., Ntamu, G. U., \& Monity, F. M. (2016). ICT utilization and students' academic performance in Christian Religious Studies in Calabar Municipality, Nigeria. The International Journal of Social Sciences and Humanities Invention, 3(11), 2925-2932. https://doi.org/10.18535/ijsshi/v3i11.1

Proctor, R., Williams, R., \& Stewart, J. (2010). If you build it, will they come? How researchers perceive and use Web 2.0. Research Information Network. http://www.rin.ac.uk/system/files/attachments/web_2.0_screen.pdf

Ross-Hellauer, T., Tennant, J. P., Banelytè, V., Gorogh, E., Luzi, D., Kraker, P., Pisacane, L., Ruggieri, R., Sifacaki, E., \& Vignoli, M. (2020). Ten simple rules for innovative dissemination of research. PLoS Comput Biol., 16(4), e1007704. https://doi.org/10.1371/journal.pcbi.1007704

Sahin, Y. G., Belta, S., \& Ercan, T. (2010). The use of internet resources by university students during their course projects elicitation: A case study. The Turkish Online Journal of Educational Technology, 9(2), 234-244. https://bit.ly/3kGkYkT

Shearer, K. (2016). Trends and innovations in research dissemination. Canadian Association of Research Libraries. https://bit.ly/35DMk6M

Shonhe, L., \& Jain, P. (2017). Information dissemination in the 21st Century: The use of mobile technologies. In N. Mnjama \& P. Jain (Eds.), Information and Knowledge for Competitiveness (pp. 425-447). Department of Library and Information Studies-University of Botswana. https://bit.ly/36JdsRb

Suleiman, I., \& Joshua, D. (2019). Awareness and utilization of internet resources and services for academic activities by the academics of tertiary institutions in Adamawa State, Nigeria. International Journal of Knowledge Content Development \& Technology, 9(2), 7-31. https://ijkcdt.net/xml/20256/20256.pdf

Tabak, R. G., Reis, R. S., Wilson, P., \& Brownson, R. C. (2015). Dissemination of health-related research among scientists in three countries: Access to resources and current practices. BioMed Research International, 2015, 179156. https://doi.org/10.1155/2015/179156

Tian, W. (2015). Knowledge dissemination through online and offline communication channels: an examination of audiences' attitudes, channel effectiveness, and engagement drivers. Master's Thesis, (University of Waterloo, Canada). https://bit.ly/38VZiPo 
Tripathy, J. P., Bhatnagar, A., Sade, H. D., Kumar, A. M. V., Zachariah, R., \& Harries, A. D. (2017). Ten tips to improve the visibility and dissemination of research for policymakers and practitioners. International Union Against Tuberculosis and Lung Disease, 7(1), 10-14. https://doi.org/10.5588/pha.16.0090

Tveden-Nyborg, S. (2013). Online scientific dissemination of knowledge blended with face-to-face learning. IASTED Multiconferences - Proceedings of the IASTED International Conference on Web-Based Education. https://doi.org/10.2316/P.2013.792-036

Uloaku, I. P. (2017). Utilization of internet resources/services by academic staff of National Water Resources Institute and Federal College of Forestry Mechanization, Kaduna, Kaduna State. Advances in Sciences and Humanities, 3(5), 54-60. https://doi.org/10.11648/j.ash.20170305.13

Vieira, A. C., Harrison, D. M., Bueno, M., \& Guimarães, N. (2018). Use of the Facebook ${ }^{\mathrm{TM}}$ social network in data collection and dissemination of evidence. Escola Anna Nery, 22(3), e20170376. https://doi.org/10.1590/21779465-ean-2017-0376

Waters, J. (2015). Snowball sampling: A cautionary tale involving a study of older drug users. Int J Soc Res Methodol., 18(4), 367-80. https://doi.org/10.1080/13645579.2014.953316

Wilson, P. M., Petticrew, M., Calnan, M. W., \& Nazareth, I. (2010). Disseminating research findings: what should researchers do? A systematic scoping review of conceptual frameworks. Implementation Science (IS), 5, 91. https://doi.org/10.1186/1748-5908-5-91

Xiao, L., \& Akin, N. (2014). Academics' opinions on Wikipedia and open access publishing. Online Information Review, 38(3), 1-28. https://doi.org/10.1108/OIR-04-2013-0062

Yammine, S. Z., Liu, C., Jarreau, P. B., \& Coe, I. R. (2018). Social media for social change in Science. Science, 360(6385), 162-63. https://doi.org/10.1126/science.aat7303

Zientek, L. R., Werner, J. M., Campuzano, M. V., \& Nimon, K. (2018). The use of Google Scholar for research and research dissemination. New Horizons in Adult Education and Human Resource Development, 30(1), 39-46. https://doi.org/10.1002/nha3.20209 


\section{FIGURES}

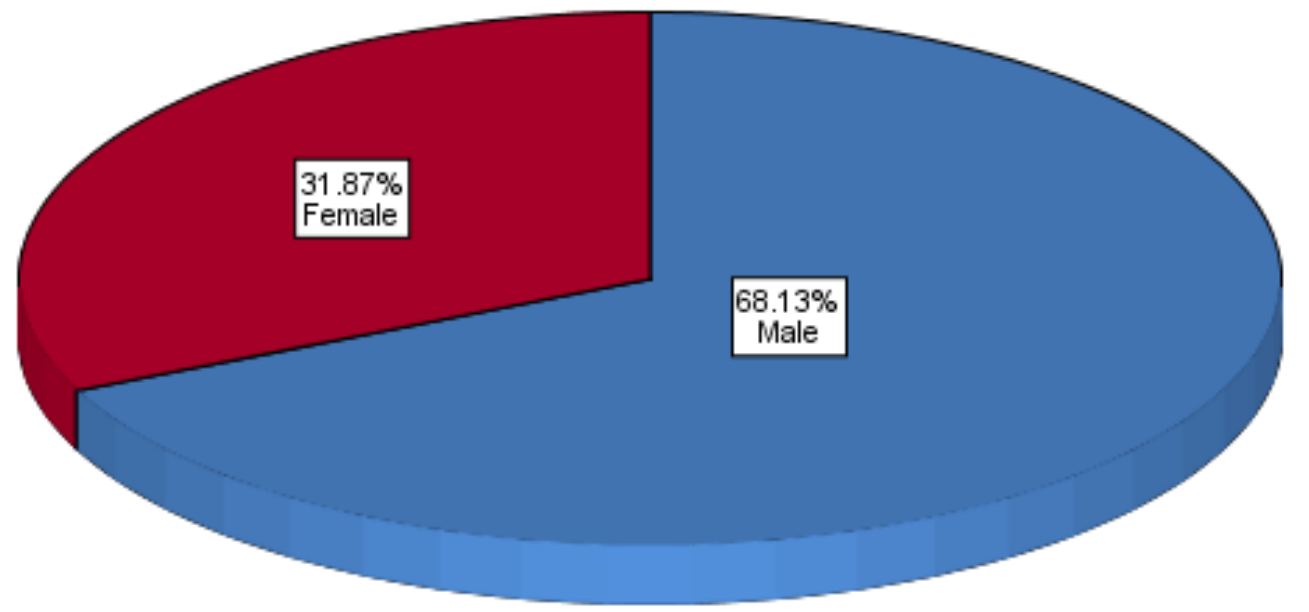

Fig. 1: Pie chart showing the gender distribution of the respondents of this study

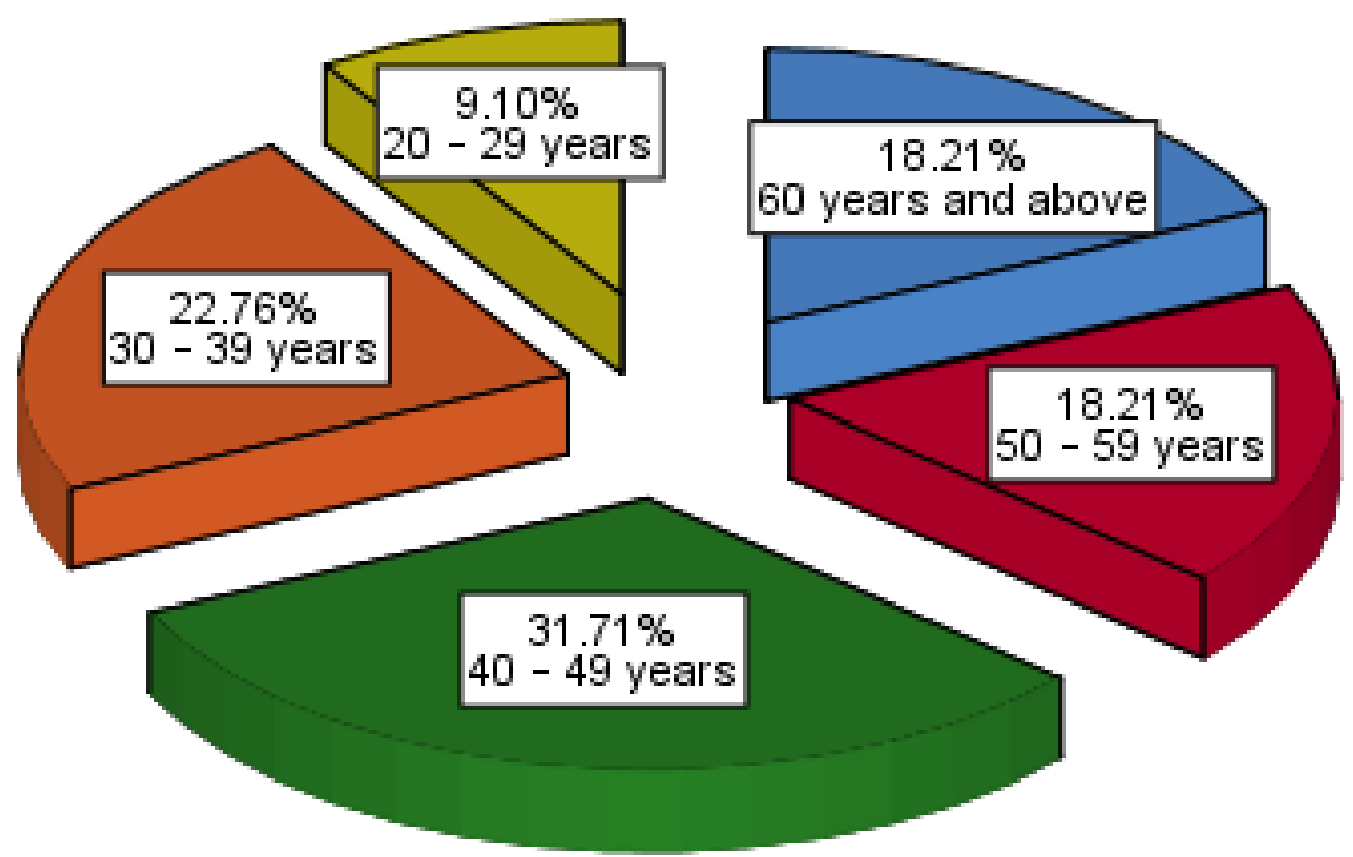

Fig. 2: Pie chart of the age distribution of the respondents of this study 


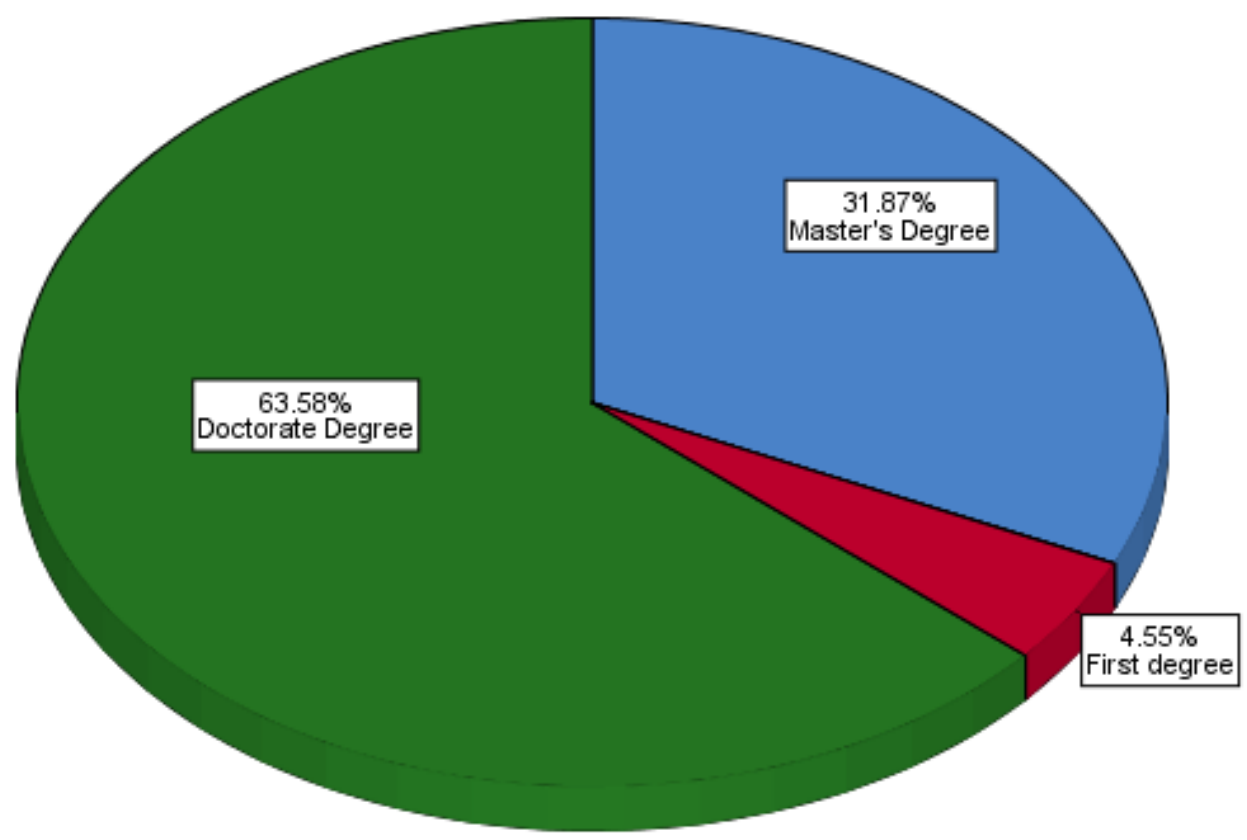

Fig. 3: Pie chart showing the distribution of respondents' Educational qualification
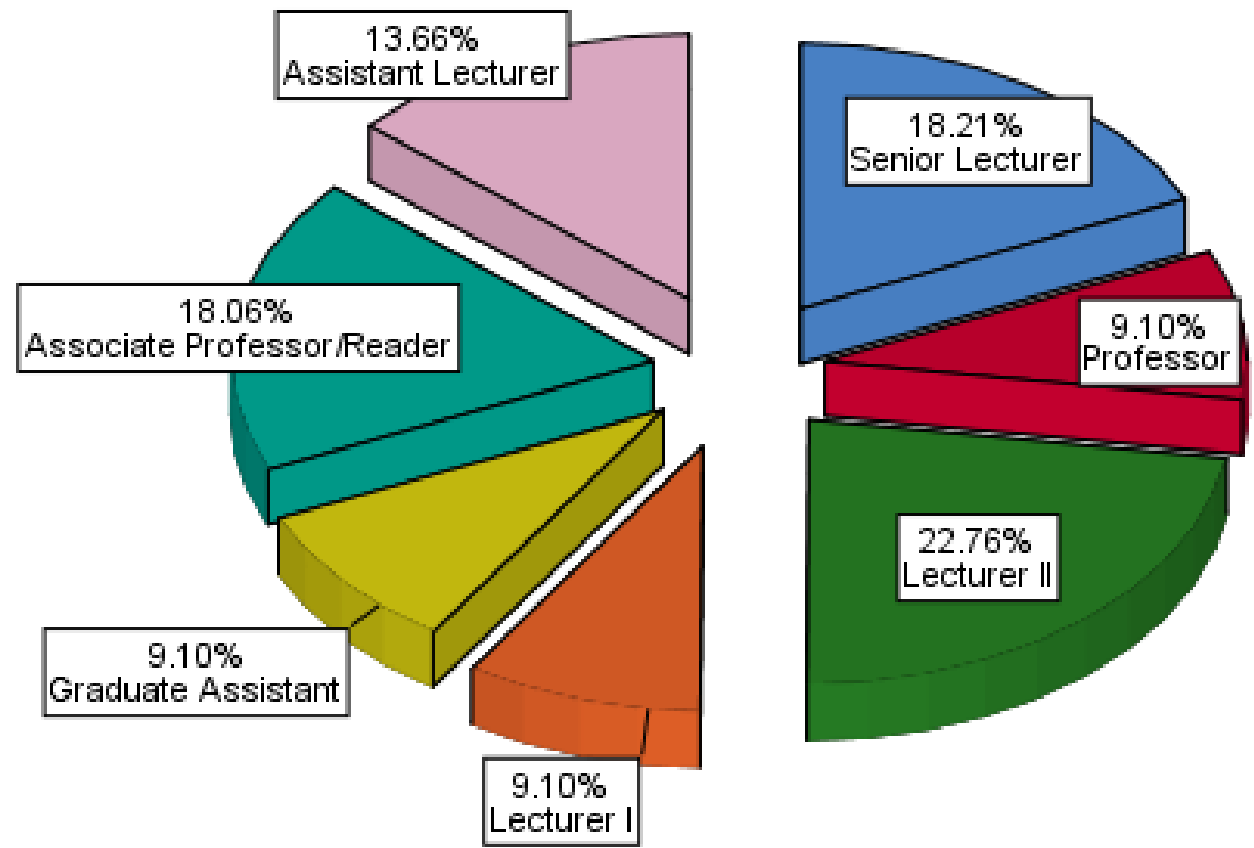

Fig. 4: Pie chart showing the distribution of respondents' academic rank 

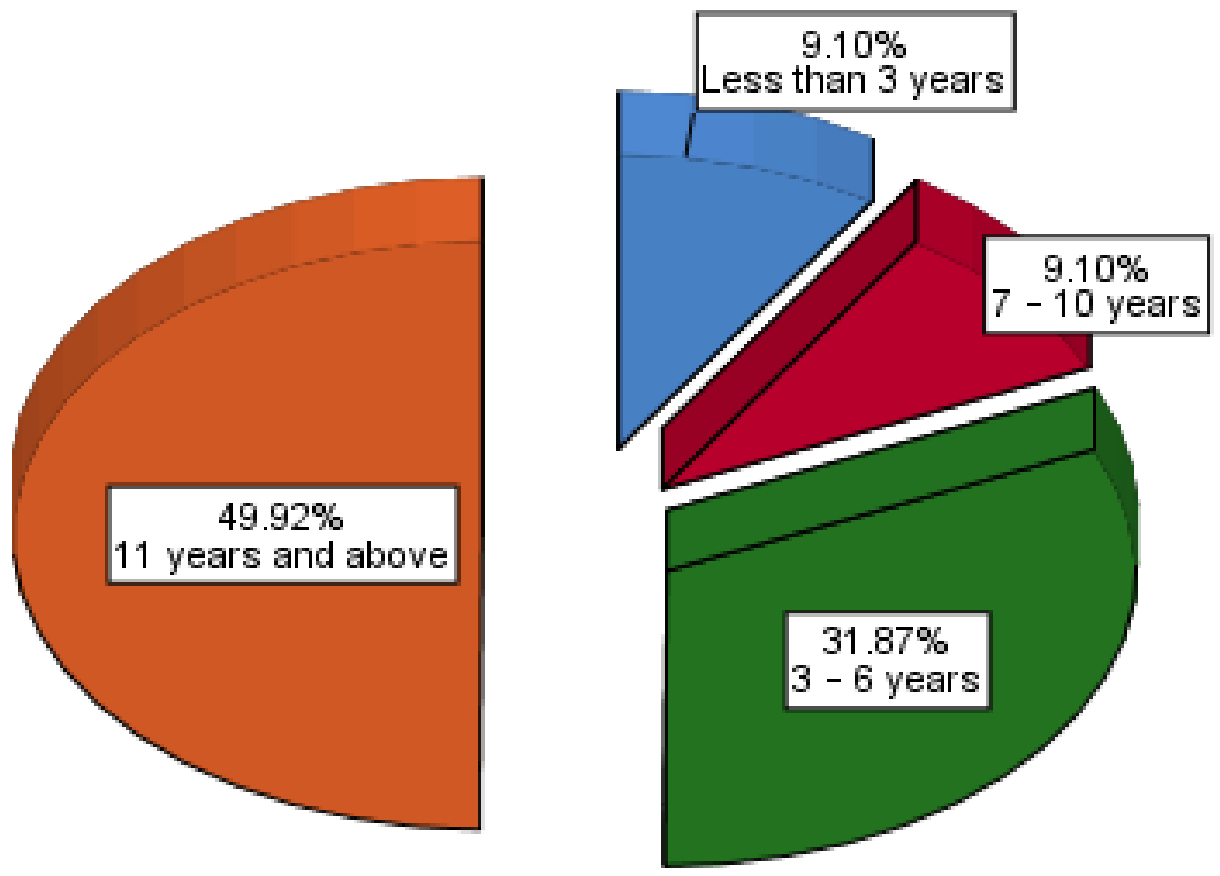

Fig. 5: Pie chart distribution of respondents' years of work experience

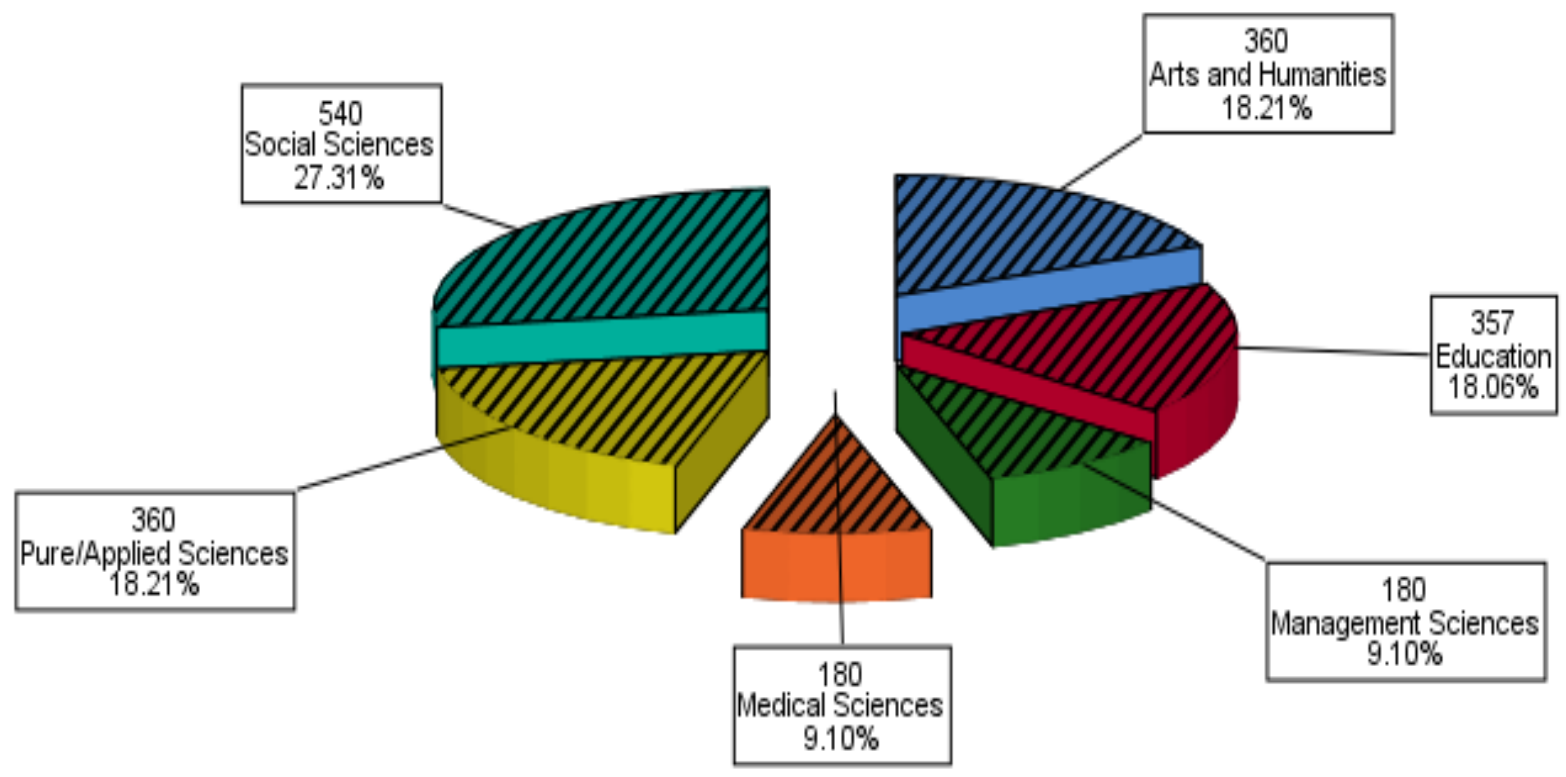

Fig. 6: Pie chart distribution showing the research areas of the respondents 


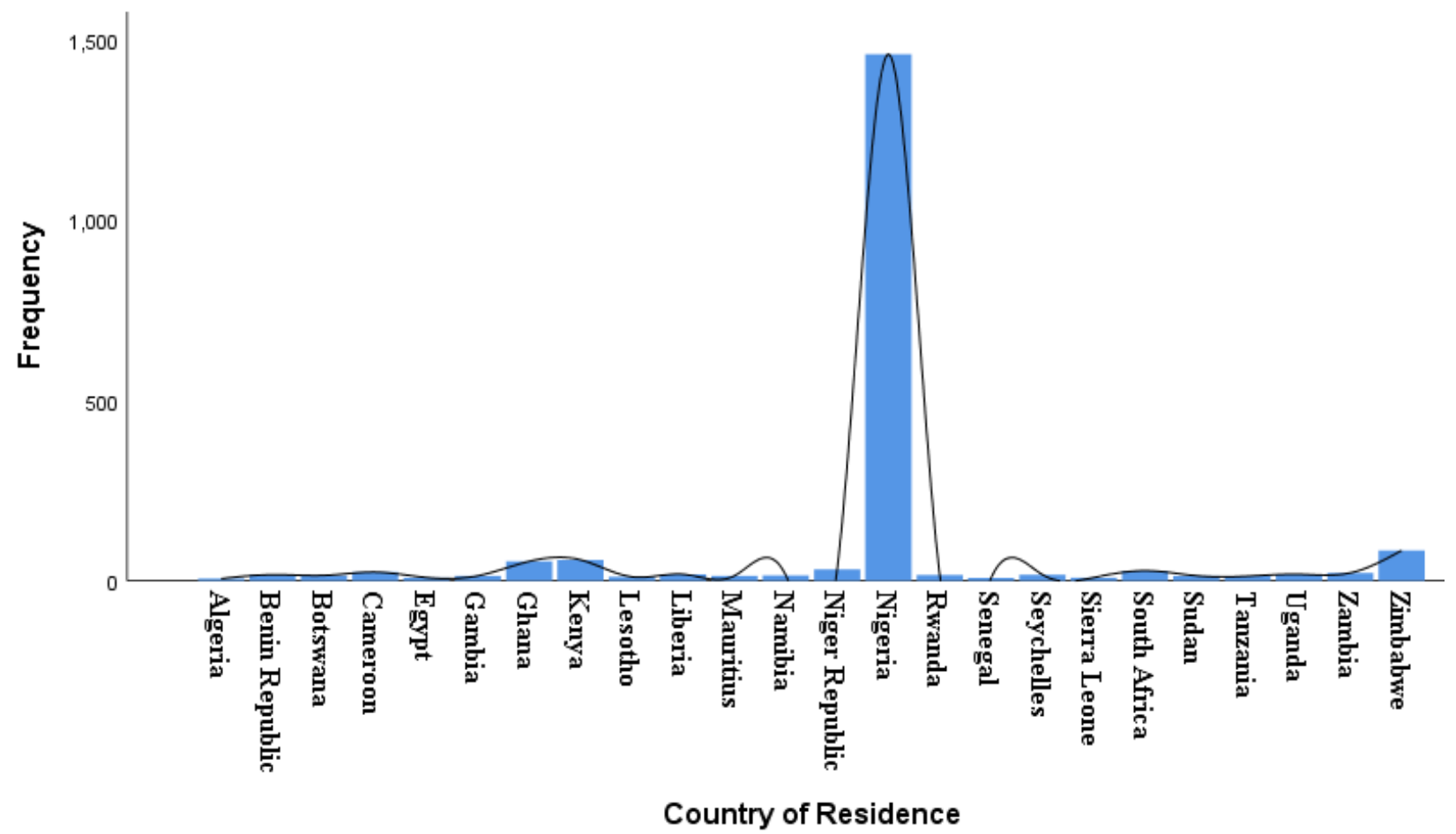

Fig. 7: Bar chart showing respondents' country of residence and the percentage

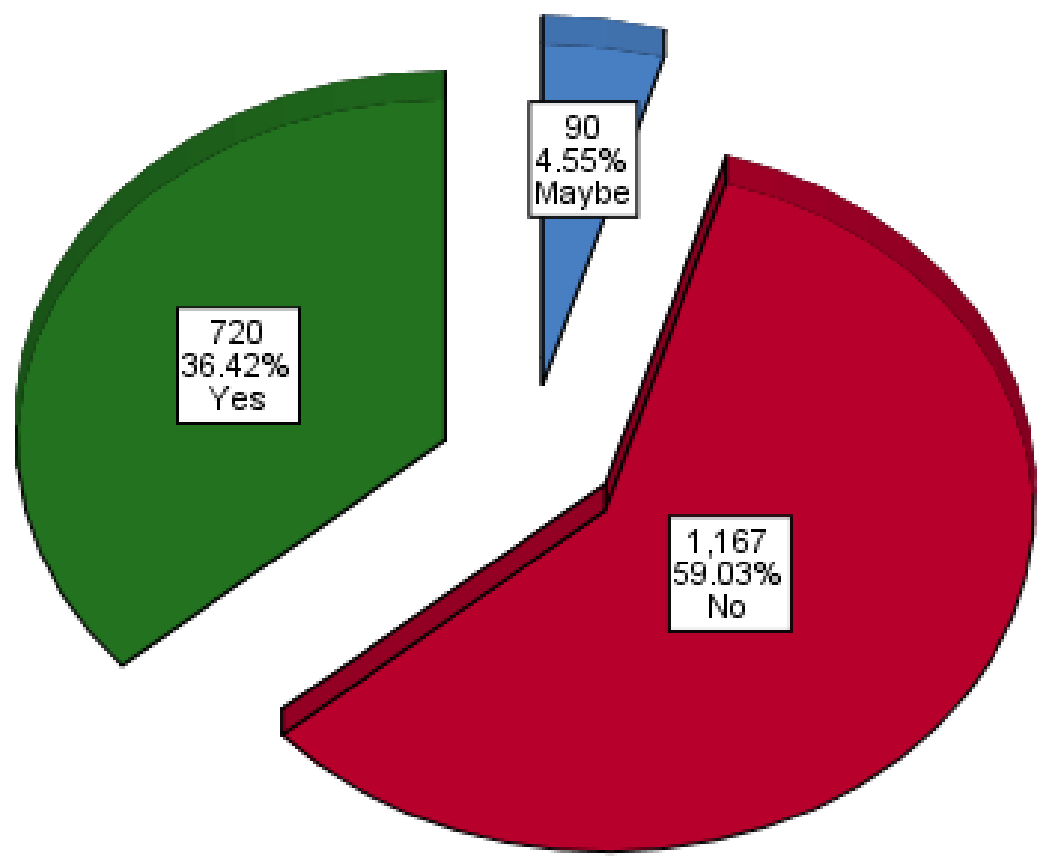

Fig. 8. Pie chart showing the extent to which academic staff agreed/disagreed that classical platforms for research dissemination are more appropriate 


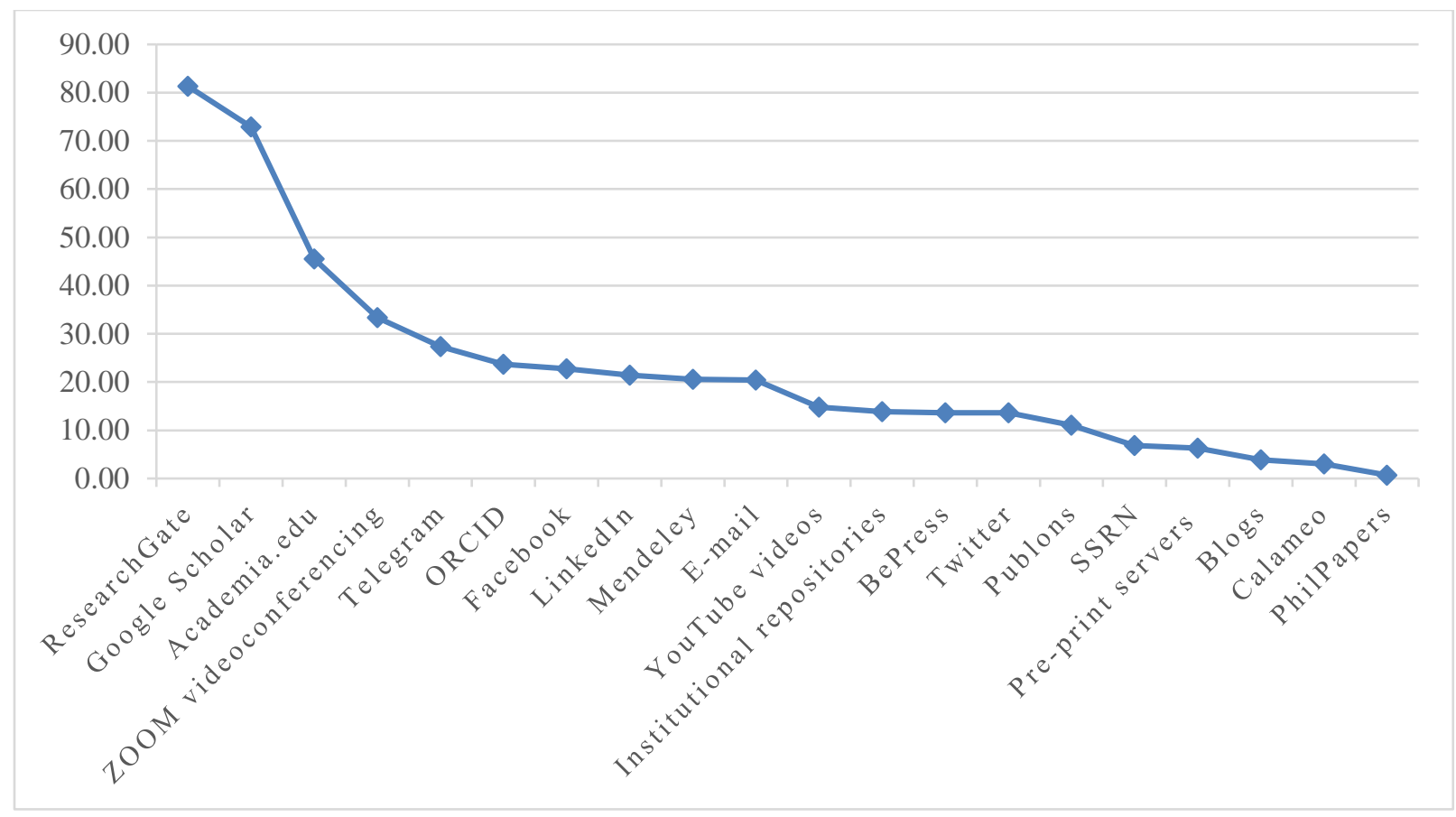

Fig. 9: Extent to which academic staff are utilising specific online platforms for RD

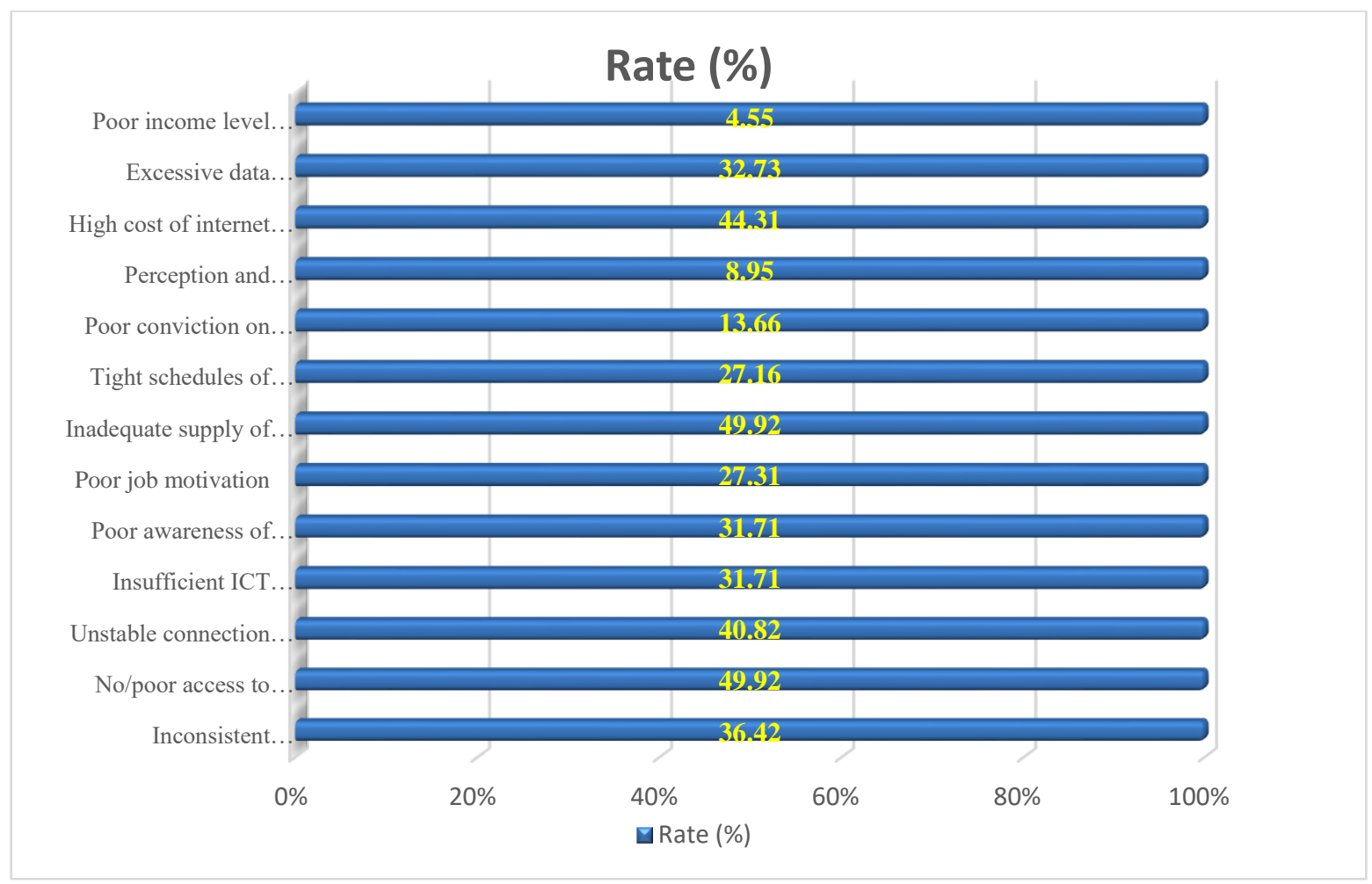

Fig. 10: Bar chart showing the challenges faced by academics in the utilization of online platforms for research dissemination in African Universities 


\section{TABLES}

Table 1: Extent of respondents' willingness to adopt online platforms for research dissemination in Africa

\begin{tabular}{|c|c|c|c|c|c|c|}
\hline$\overline{\mathrm{S} / \mathrm{N}}$ & Online platforms & Score & $\overline{\bar{X}}$ & $\mathrm{SD}$ & $\mathrm{S}^{2}$ & Remark \\
\hline$\overline{1}$ & ResearchGate & 8814 & 4.46 & .89 & .79 & High extent of willingness \\
\hline 2 & Google Scholar & 8901 & 4.50 & .78 & .61 & High extent of willingness \\
\hline 3 & Publons & 4860 & 2.46 & 1.97 & 3.88 & Low extent of willingness \\
\hline 4 & ORCID & 6027 & 3.05 & 2.01 & 4.05 & High extent of willingness \\
\hline 5 & Mendeley & 6570 & 3.32 & 1.91 & 3.66 & High extent of willingness \\
\hline 6 & SSRN & 4680 & 2.37 & 2.01 & 4.05 & Low extent of willingness \\
\hline 7 & Academia.edu & 7290 & 3.69 & 1.54 & 2.38 & High extent of willingness \\
\hline 8 & Calameo & 3870 & 1.96 & 1.72 & 2.95 & Low extent of willingness \\
\hline 9 & BePress & 3960 & 2.00 & 1.76 & 3.09 & Low extent of willingness \\
\hline 10 & Facebook & 5670 & 2.87 & 1.98 & 3.93 & High extent of willingness \\
\hline 11 & Twitter & 4860 & 2.46 & 1.75 & 3.06 & Low extent of willingness \\
\hline 12 & LinkedIn & 5670 & 2.87 & 1.79 & 3.20 & High extent of willingness \\
\hline 13 & Telegram & 5940 & 3.00 & 1.53 & 2.35 & High extent of willingness \\
\hline 14 & $\mathrm{~B} \log \mathrm{s}$ & 5220 & 2.64 & 1.82 & 3.32 & High extent of willingness \\
\hline 15 & YouTube videos & 5940 & 3.00 & 1.88 & 3.54 & High extent of willingness \\
\hline 16 & E-mail & 8091 & 4.09 & 1.16 & 1.36 & High extent of willingness \\
\hline 17 & PhilPapers & 3960 & 2.00 & 1.73 & 3.00 & Low extent of willingness \\
\hline 18 & Institutional repositories & 6840 & 3.46 & 1.72 & 2.96 & High extent of willingness \\
\hline 19 & ZOOM video conferencing & 7020 & 3.55 & 1.90 & 3.60 & High extent of willingness \\
\hline \multirow[t]{2}{*}{20} & Pre-print servers & 5580 & 2.82 & 1.97 & 3.87 & High extent of willingness \\
\hline & Average & 5839 & 3.03 & 1.69 & 2.98 & High extent of willingness \\
\hline
\end{tabular}


Table 2: Online platforms utilized by academic staff for research dissemination and the rate of utilisation

\begin{tabular}{llll}
\hline S/N & Online platforms & Frequency $(\mathrm{f})$ & Rate $(\%)$ \\
\hline 1 & ResearchGate & 1608 & 81.34 \\
2 & Google Scholar & 1441 & 72.89 \\
3 & Academia.edu & 900 & 45.52 \\
4 & ZOOM video conferencing & 660 & 33.38 \\
5 & Telegram & 540 & 27.31 \\
6 & ORCID & 468 & 23.67 \\
7 & Facebook & 450 & 22.76 \\
8 & LinkedIn & 423 & 21.40 \\
9 & Mendeley & 407 & 20.59 \\
10 & E-mail & 403 & 20.38 \\
11 & YouTube videos & 293 & 14.82 \\
12 & Institutional repositories & 274 & 13.86 \\
13 & BePress & 270 & 13.66 \\
14 & Twitter & 270 & 13.66 \\
15 & Publons & 219 & 11.08 \\
16 & SSRN & 136 & 6.88 \\
17 & Pre-print servers & 125 & 6.32 \\
18 & Blogs & 77 & 3.89 \\
19 & Calameo & 60 & 3.03 \\
20 & PhilPapers & 14 & 0.71 \\
\hline
\end{tabular}

Table 3: Challenges faced by academic staff in the utilisation of online platforms for RD

\begin{tabular}{clcc}
\hline S/N & \multicolumn{1}{c}{ Challenges } & F & Rate (\%) \\
\hline 1 & Inconsistent electricity supply & 720 & 36.42 \\
2 & No/poor access to internet facilities at home & 987 & 49.92 \\
3 & Unstable connection by internet service providers & 807 & 40.82 \\
4 & Insufficient ICT knowledge or internet operational skills & 627 & 31.71 \\
5 & Poor awareness of online platforms for research dissemination & 627 & 31.71 \\
6 & Poor job motivation & 540 & 27.31 \\
7 & Inadequate supply of internet at the workplace & 987 & 49.92 \\
8 & Tight schedules of duties and operations & 537 & 27.16 \\
9 & Poor conviction on the benefits of electronic platforms & 270 & 13.66 \\
10 & Perception and resistance (e.g., the internet is meant for younger generations) & 177 & 8.95 \\
11 & High cost of internet bundle and subscription rates & 876 & 44.31 \\
12 & Excessive data consumption by internet service providers & 647 & 32.73 \\
13 & Poor income level which hinders the procurement of cutting-edge devices and & 90 & 4.55 \\
& gadgets to facilitate online presence & & \\
\hline
\end{tabular}

